\title{
Characterization polyethylene terephthalate nanocomposites mixing with nano-silica and titanium oxide
}

\author{
Mircea A. Rusu ${ }^{1,}$, Dan Leordean ${ }^{1}$, Cosmin Cosma ${ }^{1}$, Miuta Filip ${ }^{2}$, Marioara \\ Moldovan $^{2}$, Laura Silaghi-Dumitrescu ${ }^{2}$ and Olga Hilda Orasan ${ }^{3}$ \\ ${ }^{1}$ Technical University of Cluj-Napoca, Faculty of Machine Building, Cluj-Napoca, Romania \\ ${ }^{2}$ Babes Bloyai University - Raluca Ripan Institute of Chemistry Research, Cluj-Napoca, Romania \\ ${ }^{3}$ University of Medicine and Pharmacy "Iuliu Hatieganu", Cluj-Napoca, Romania
}

\begin{abstract}
Polyethylene terephthalate (PET) based nanocomposites containing nano-silica (Aerosil (Degusa)) and titanium oxide $\left(\mathrm{TiO}_{2}\right.$ (Merk)) were prepared by melt compounding. Influence of nano-silica and titanium oxide on properties of the resulting nanocomposites was investigated by scanning electron microscopy (SEM), Fourier transform infrared spectroscopy (FTIR) and atomic force microscopy (AFM). The possible interaction between nano-silica and titanium oxide particles with PET functional groups at bulk and surface was elucidated by transmission of FTIR-ATR spectroscopy. AFM studies of the resulting nanocomposites showed an increased surface roughness compared to pure PET. SEM images illustrated that nano-silica particles have tendency to migrate to the surface of the PET matrix much more than titanium oxide powder.
\end{abstract}

\section{Introduction}

The presence of large quantities of mixed plastic waste, impurities and contamination are the main challenge for efficient recycling of plastic materials from packaging. In the last years the efficient management of different waste streams (selective collection, automatic separation) has enabled the recovery of large volumes of relatively clean and homogeneous polymeric elements that are viable for mechanical recycling. Polymers are the most widely used materials in various fields due to their valuable characteristics such as good mechanical properties, low density, rather low cost, and also easy to process [1-4]. The total production of plastics is more than 230 million tonnes per year and to alleviate this waste, many solutions have been proposed for the management of plastics waste, such as recycling, incineration and degradation of materials.

The most common types of polymers are: PET (polyethylene terephthalate), HDPE (high density polyethylene), PVC (polyvinyl chloride), LDPE (low density polyethylene), PP (polypropylene), PS (polystyrene). The efficient treatment of polymers waste is still a difficult challenge. The traditional methods such as combustion or burying underground

*Corresponding author: mcrusu2206@yahoo.com 
show a negative effect on the environment like formation of dust, fumes and toxic gases in the air, and the pollution of underground water and other resources. We can obtain the substantial enhancements of mechanical, thermal, optical and barrier properties using the nanofillers [5-6]. The nano-additives increase the interphase surface of components and superficial area/volume ratio leading to improvement of overall performances. If a comparison is made between blending recycled polymers with nanomaterials $[7,8]$ some studies have found that a small load is sufficient to develop excellent properties without greatly increasing density and cost. It has been found that they have acted as a nuclear agent and accelerated the rate of crystallization of the polymer, increasing the melting resistance and viscosity of the polymers [9-14].The aim of this study is to develop, characterize and investigate, according to the filler content, blends of recycled PET with nano-silica and titanium oxide, in order to obtain materials used in the manufacture of parts used for design verification, shape verification, models for casting and medical application processes.

\section{Materials \& Methods}

The PET samples used in this study come from numerous commercial waste packaging materials (cups, glasses, bottles, etc.) made from these polymers. Nano-silica particles (Aerosil) were supplied by the German, Degussa Company and titanium oxide by Merck. PET samples with nano-silica particles and titanium oxide were mixed and dried, prior to the melting process. Each nanocomposites was prepared by mixing and was kept at $210^{\circ} \mathrm{C}$ for 30 minutes, in order to ensure proper viscosity for the mixing process. The content of nano-silica and titanium particles in the matrix was ensured to be $10 \%$ by weight (wt $\%$ ). Specimens to be tested were further processed by the aid of a laboratory press at a pressure of 220 psi(Fig.1.). The temperatures of both upper and lower plates of the press were kept at $220^{\circ} \mathrm{C}$. The chemical structure of the waste plastics PET, samples PET/with nano-silica and PET/titanium was confirmed by recording their IR spectra, SEM Microscopy and AFM. Characterization of the resultant nanocomposites was carried out using a FTIR spectrophotometer (JASCO, 610), equipped with a reflection ATR accessory for reflection mode. All the ATR spectra of PET/nano-silica and PET/titanium nanocomposites were comparated with the spectra of pure PET. The recorded wavenumber range was from 450 to $4000 \mathrm{~cm}^{-1}$. Surface morphology analyses of the nanocomposite were carried out by the aid of a scanning electron microscope (SEM, FEI Inspect S, Netherlands) and atomic force microscopy (AFM, Veeco, Multimode type.).

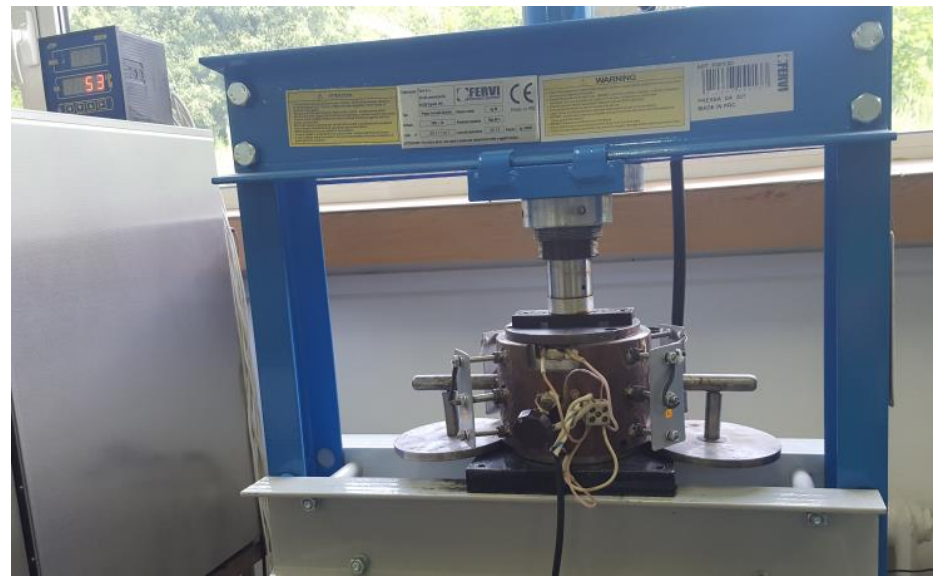

Fig. 1. Laboratory press with plates. 


\section{Results and discussions}

The recording of the spectra on the recycled samples may change depending on the morphology and the sample processing history, and the relative intensities of the low-tomedium intensity bands can be obtained. The chemical structure of the (PET) polymers, melted with silica and $\mathrm{TiO}_{2}$ was confirmed by recording their IR-ATR spectra. The Fourier transform infrared (IR-ATR) results of samples in absorption mode are shown in table 1.

The infrared spectrum is known to contain information of the microstructure. The microstructure is a representation of the characteristics of the material, whether it is physical, chemical or mechanical. It may be noted that breadth and shape of the infrared bands are representation of the manner in which molecules relax from the vibrational excited state reach upon the absorption of an (infrared) photon.

Table 1. Infrared spectroscopic data of waste pet bottles $\left(\mathrm{cm}^{-1}\right)$.

\begin{tabular}{|c|c|c|c|c|c|c|c|c|c|}
\hline $\begin{array}{c}\text { Band } \\
\text { Name/ } \\
\text { sample } \\
\text { s }\end{array}$ & $\begin{array}{c}\text { ArC } \\
\text { Wag } \\
\mathrm{g}\end{array}$ & $\begin{array}{c}\text { ArCH } \\
\text { Out of } \\
\text { plane }\end{array}$ & $\begin{array}{c}\text { O-C-C } \\
\text { Asymm }\end{array}$ & $\begin{array}{c}\text { C-C- } \\
\text { O } \\
\text { Asym } \\
\mathrm{m}\end{array}$ & $\begin{array}{c}\text { C-H } \\
\text { def. in } \\
\text { alkane }\end{array}$ & $\begin{array}{c}\text { C-H } \\
\text { bendin } \\
\mathrm{g}\end{array}$ & $\begin{array}{c}\text { Ar C-C } \\
\text { bond }\end{array}$ & $\begin{array}{c}\mathrm{C}=\mathrm{O} \\
\text { Ester }\end{array}$ & $\begin{array}{c}\mathrm{C}-\mathrm{H} \\
\text { Asym } \\
\mathrm{m}\end{array}$ \\
\hline PET & 724 & 873 & $\begin{array}{c}1091 \\
1128\end{array}$ & 1238 & $\begin{array}{c}1340 \\
1402\end{array}$ & 1453 & 1501 & 1709 & 2960 \\
\hline
\end{tabular}

The FT-IR spectra of PET confirms the presence of a carbonyl group at $1709 \mathrm{~cm}^{-1}$. The peak at $1238 \mathrm{~cm}^{-1}$ is due to the asymmetric C-C-O stretching involving the carbon in aromatic ring. The aromatic $\mathrm{C}-\mathrm{H}$ wagging appears at $724 \mathrm{~cm}^{-1}$. The peak at $873 \mathrm{~cm}^{-1}$ corresponds to aromatic $\mathrm{C}-\mathrm{H}$ out of plane bending. The $\mathrm{O}-\mathrm{C}-\mathrm{C}$ asymmetric stretching is split at 1128 and $1091 \mathrm{~cm}^{-1}$. There are peaks at $1453 \mathrm{~cm}^{-1}$ (C-H bending), $1501 \mathrm{~cm}^{-1}$ (aromatic C-C stretching) $2960 \mathrm{~cm}^{-1}$ (C-H asymmetric stretching). Peak at $1402 \mathrm{~cm}^{-1}$ and $1340 \mathrm{~cm}^{-1}$ is due to deformation $\mathrm{C}-\mathrm{H}$ alkane. Infrared spectra of the $\mathrm{SiO}_{2}$ used in this study indicates the presence of $\mathrm{Si}-\mathrm{O}-\mathrm{Si}$ band, well reflected in nanosilica particles, as a strong bending band at about 1012-1200 $\mathrm{cm}^{-1}$. The infrared spectra for composites $\mathrm{PET} / \mathrm{SiO}_{2}$ showed the weak $\mathrm{C}-\mathrm{H}$ stretching, $\mathrm{C}-\mathrm{H}$ bending and moderately intense $\mathrm{C}-\mathrm{C}$ out of plane bending vibrations of the benzene rings in polyester appear at 3054, 793, 848 and $721 \mathrm{~cm}^{-1}$ respectively. The infrared spectra of the $\mathrm{PET} / \mathrm{TiO}_{2}$ nanocomposites indicate $1710 \mathrm{~cm}^{-1}$ band characteristic of the vibration of the carbonyl $(\mathrm{C}=\mathrm{O})$ of the ester group present in the polymer.

In the present study, the morphology of the surfaces of the blends was analyzed with SEM. The particles were very fine, the morphology and size of the powder were determined using SEM images, which revealed spherical particles and a uniform dispersion in the polymer (Fig.2).

Figure 2 (a-e) shows SEM micrographs of the surfaces of pure PET together with various $\mathrm{PET} / \mathrm{SiO}_{2}, \mathrm{PET} / \mathrm{TiO}_{2}$ composites. As can be seen, pure PET has a relatively smooth and uniform surface. Most of the crystallites are irregularly shaped and they seem to interlock with each other. The radial texture can be observed at some locations. However, the boundaries between the crystallites are not clear. As the polymer chains next to the nanoparticles are likely to be tethered onto the particules surfaces, a strong interaction may exist between the polimer and crystallites that prevents the boundary areas from being etched away. The strategy of using nanoparticles to modify structure and bulk properties of performance materials is well known. In general, the ability of additives to migrate to the surface is defined by several factors such as size, composition, mobility, functionalities and molecular architecture. 


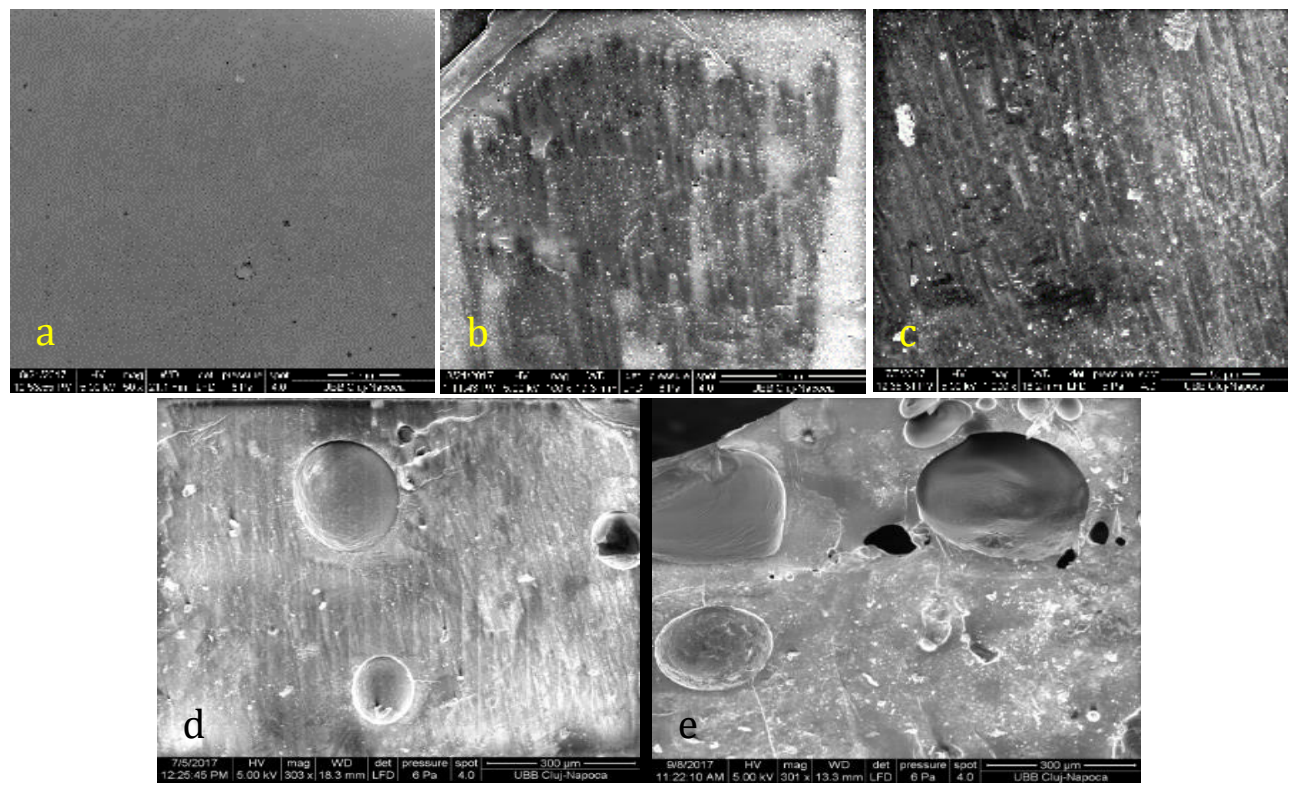

Fig. 2. Scanning electron images of various composites: (a) pure PET, (b) PET/ $10 \%$ nano-silica, c) PET $/ 10 \%$ titanium oxide; Images in the section: (d) PET/10\% hydrophilic nano-silica, (e) PET $/ 10 \%$ titanium oxide.

As mentioned previously, the FTIR analysis of the samples illustrate that PET, $\mathrm{SiO}_{2}$ and $\mathrm{TiO}_{2}$ particles have some interfacial interactions within the PET matrix. However, it seems that these interactions are not strong enough to enable good dispersion of the particles within the PET matrix.
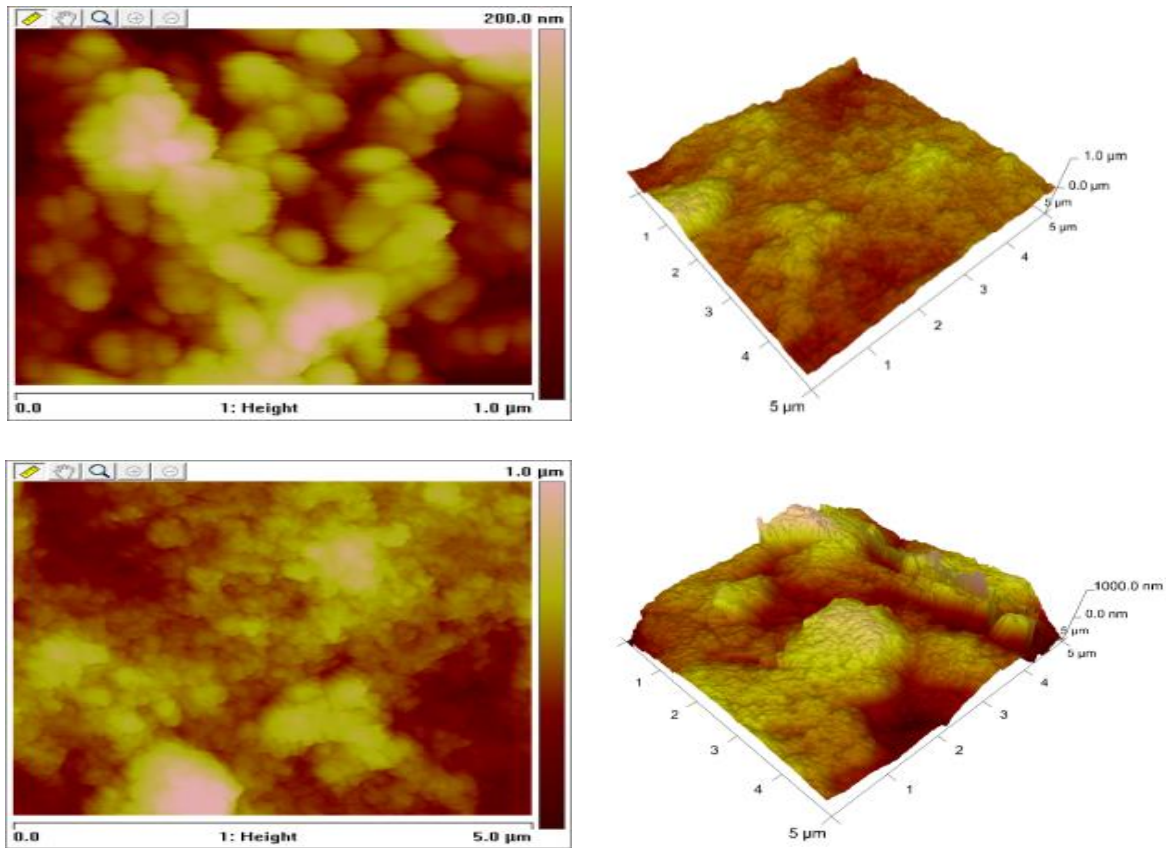

Fig. 3. Images of atomic force microscopy for various composites: (a) PET/10\% nano-silica (b) $\mathrm{PET} / 10 \% \mathrm{TiO}_{2}$. 
Other authors have confirmed this phenomenon in cases where nano-silica and $\mathrm{TiO}_{2}$ was incorporated into multilayer organic coatings [15-22].

Addition of nano particles to the PET matrix leads to various chain interactions enabling formations of aggregates and agglomerates on the surface of PET composites. The presence of these particles results in increased surface roughness which is in good agreement with the AFM images. Such agglomerations are less evident for $\mathrm{SiO}_{2} / \mathrm{PET}$ composite causing smoother surfaces comparing with $\mathrm{TiO}_{2} / \mathrm{PET}$ composites. Figure 3 shows the presence of agglomerations on the surface of the nanocomposites investigated.

Plastics besides polymers also contain additives, dyes and copolymer mixtures that can cause problems and are difficult to separate. By recycling them, after several processing cycles, the structure of polymer is degraded introducing poorer mechanical properties than those of a virgin one $[10,11]$ obtaining inferior quality products.

In addition to the chemical contaminants and degradation products generated during the first processing and use, impurities, such as microscopic particles, increase the frequency of defects in the polymer resulting in the quality degradation in the recycling flow. Because sorting, separation and cleaning processes are the most important and most difficult to achieve for the recycled polymer, small amounts of nano powder were added to the polymer, which can be an efficient recycling technique for polymers. Various nanoparticles such as nano-silica and $\mathrm{TiO}_{2}$, have been used for recycling which should be developed for all polymer waste.

However, with the goal of successful and economic recycling, more research needs to be done on the whole aspect of the recycling process to enhance competitiveness and optimization of the melt mixing process in these systems. The first step could be to improve interfacial interaction and adhesion in nanocomposites, particle surface modification procedures, which should lead to a better compatibility with the surface of the polymer.

\section{Conclusions}

Products prepared by the addition of nanoparticles to recycled polymers can offer unexpected combinations of improved properties, low weight, easy processing and low costs that are not readily available and concurrently with other industrial products. Effects of the nanoparticle type on surface properties nanocomposites were studied

Obtained results suggest that there are more and larger silica and titanium oxide particles present at the PET/nanocomposite, causing increased surface scattering and roughness. FTIR-ATR studies have shown interfacial interactions between in the PET matrix with $\mathrm{SiO}_{2}$ and $\mathrm{TiO}_{2}$ nanoparticles, but are not strong enough to allow good dispersion of the particles in the PET matrix. This result is incidentally consistent with our other results obtained from AFM, and SEM analyses.

This research was supported by the AM-CIR project, PN-II-RU-TE-2014-4-1157, no. 37/01.10.2015 financed from the UEFISCDI by the Romanian Government and also by the HORIZON 2020 AMaTUC project (GA 691787) financed from EU.

\section{References}

1. A. Leszczy' nska, J. Njuguna, K. Pielichowski, J.R. Banerjee, Thermochim. Acta, 453, 75-96 (2007)

2. S. Sinha Ray, M. Okamoto, Prog. Polym. Sci., 28, 1539-1641 (2003)

3. Ramezani-Dakhel H, Garmabi H. Journal of Applied Polymer Science, 118, 969-979 (2010)

4. S.S. Pesetskii, S.P. Bogdanovich, N.K. Myshkin, J. Fric, Wear, 28, 457-475 (2007) 
5. J. Njuguna, K. Pielichowski, S. Desai, Polym. Advan. Technol., 19, 947-959 (2008)

6. J. Ma, J. Xu, J.H. Ren, Z.Z. Yu, Y.W. Mai, Polymer, 44, 4619-4624 (2003)

7. D. Burgentzle', J. Duchet, J.F. Ge' rard, A. Jupin, B. Fillon, J. Colloid Interf. Sci., 278, 26-39 (2004)

8. W.Li, J.Karger-Kocsis, R.Thomann: Journal of Polymer Science Part B: Polymer Physics, 47, 1616-1624 (2009)

9. S.C. Chung, W.G. Hahm, S.S. Im, Macromol. Res., 10, 221-229 (2002)

10. L. M.Robeson, Polymer blends: A comprehensive review. Hanser, Munich (2007).

11. W. Liu, X. Tian, P. Cui, Y. Li, K. Zhang, Y. Yang, J. Appl. Polym. Sci., 91, 1229$1232(2004)$

12. Y. Zare, H. Garmabi , Journal of Applied Polymer Science., 123, 2309-2319 (2012)

13. S. H. Jafari1, A. Kalati-vahid, H. A. Khonakdar, A. Asadinezhad, U. Wagenknecht, D. Jehnichen, eXPRESS Polymer Letters, 6, 148-158 (2012)

14. S.I.S Shahabadi, H. Garmabi. Polymer Letters, 6, 657-671 (2012)

15. M. Goto, M. Sasaki, T. Hirose, Journal of Materials Science, 41, 1509-1515 (2006)

16. T.Y Tsai, C.H Li, C.H Chang, W.H. Cheng, C.L Hwang, R.J. Wu, Adv Mater, 17, 1769-1773 (2005)

17. S.C. Chung, W.G. Hahm, and S.S. Im, Macromolecular Research, 10, 221-229 (2002)

18. O.H Lin., H.M Akil., Z.A.M Ishak, Polym. Compos., 30,1693-1700 (2009)

19. J. Vega-Baudrit, M. Sibaja-Ballestero, P. Va'zquez, R. Torregrosa-Macia, J.M. Martı'n-Martı'nez, Int. J. Adhes., 27, 469-479 (2007)

20. Y.G. Lee, C. Oh, D.W. Kim, Y.D. Jun, S.G. O, J. Ceram. Process. Res., 9, 302-306 (2008)

21. C.S. Sipaut, N. Ahmad, R. Adnan, I.A.B. Rahman, M.A. Bakar, J. Ismail, C.K. Chee, J. Appl. Polym. Sci., 7, 27-34 (2007)

22. K. Han, M. Yu, J. Appl. Polym. Sci., 100, 1588-1593 (2006) 